This paper is published in the open archive of Mid Sweden University

DIVA http://miun.diva-portal.org

with permission of the publisher

Citation for the peer-reviewed published paper:

Torgnysdotter A, Wågberg L. Influence of electrostatic interactions on fibre/fibre joint and paper strength. ; Nordic Pulp \& Paper Research Journal. 2004;19(4):440-447.

URL to article at publishers site:

http://dx.doi.org/10.3183/NPPRJ-2004-19-04-p440-447 


\title{
Influence of electrostatic interactions on fibre/fibre joint and paper strength
}

\author{
Annsofie Torgnysdotter, Mid Sweden University, Sundsvall, and Lars Wågberg, Royal Institute of Technology, KTH, Stockholm, Sweden
}

KEYWORDS: Bonded area, Chemical bonds, Dry strength, Electrostatic charge, Joints, Regenerated cellulose, Strain, Swelling

SUMMARY: A study was undertaken to explore the influence of electrostatic interactions between the fibres during sheet forming and sheet consolidation on the strength of both the fibre/fibre joints and the paper. To establish this relationship, the joint strength between individual fibres was determined and compared with the strength of sheets made from these corresponding fibres. Regenerated cellulose fibres with their charge varied by carboxymethylation (anionic fibres) and by treatment with glycidyltrimethylamoniumchloride (GTAC) (cationic fibres) were investigated. In addition to joint strength and sheet strength measurements, the fibre charge together with wet fibre flexibility and fibre swelling, were evaluated for the differently treated fibres.

The joint strength between individual fibres decreased with increasing ionic strength whereas the sheet strength measurements showed an increase in strength with increasing ionic strength for the bulk charged fibres. These results were found for both anionic and cationic bulk charged fibres. The wet flexibility of the fibres increased with increasing bulk charge, but there was no change in flexibility with an increase in salt concentration. Furthermore, there was no change in flexibility by increasing the surface charge of the fibres. It is suggested that the increase in sheet strength with increasing charge of the fibre is due to increasing joint strength and that the decrease in joint strength with increasing salt concentration is due to a decrease in the surface swelling of the fibres and hence a less favourable interaction between the fibres.

The increase in sheet strength for the bulk charged fibres with increasing salt concentration is probably caused by an increased probability for joint formation in the fibre/fibre contacts due to decreased electrostatic repulsion between the fibres. This is discussed in terms of a balance between electrostatic repulsion and attractive capillary forces between the fibres during forming and consolidation of the paper.

ADDRESSES OF THE AUTHORS: Annsofie Torgnysdotter, (annsofie.torgnysdotter@mh.se): Mid Sweden University, FSCN, 85170 Sundsvall, Sweden. Lars Wågberg, (wagberg@pmt.kth.se): KTH, Fibre and Polymer Technology, Div. Fibre Technology, Drottning Kristinas v 53, SE-100 44 Stockholm, Sweden.

The web forming in combination with the densification of the paper during pressing and drying are crucial macroscopic processes that will determine how well the inherent properties of the fibres can be utilised in the formed paper. Previous investigations have shown the importance of fibre flexibility, supposed to influence the number of joints between the fibres (Wahlström, 1988), and the strength of these joints (Page 1969; Stratton and Colson 1990; Torgnysdotter and Wågberg 2003) on the strength of the formed paper. In summary this means that the strength of the paper will be affected by the a) joint strength between individual fibres. This joint strength will, in turn, be determined by the work of adhesion caused by molecular interactions in the contact zone between the fibres and the molecular dimensions of this contact zone

b) number of joints per unit volume of the sheet

c) fibre strength

d) existence of fracture initiation zones on a network level, i.e. the macroscopic formation of the sheet

In a recent publication (Torgnysdotter and Wågberg 2003) the different chemical factors contributing to the thermodynamic work of adhesion was discussed. However, it is well known (Kendall 2001') that the real work of adhesion is often much larger than the thermodynamic work of adhesion. The main reason for this difference is often referred to as a slow intermixing of surface layers of the interacting surfaces or a re-conformation of the molecules on the surfaces in contact, to yield a more favourable molecular contact. Another reason for the change in adhesion could be a very small scale roughness of the surfaces that actually increases the molecular contact area (Kendall 2001²) in the contact zone. However, time is needed to allow for any adjustment of the surfaces to each other on this sub-micrometer level and therefore a large hysteresis between the loading and un-loading work of adhesion is detected. The ability of the surfaces to adjust to each other will be determined by the mechanical properties of the surface layers, i.e. their visco-elastic properties. For fibres, these properties are highly dependent on the moisture content where the chemical composition of the fibres will affect the moisture absorption and hence the mechanical properties of the surface layers.

In order to form strong contacts between the fibres it is important to have both a large molecular contact area between the fibres and a large interaction between the fibres in this contact zone. Earlier investigations have also shown that a highly charged fibre wall leads to a higher degree of swelling of the fibres (Grignon and Scallan 1980; Lindström 1986; Lindström and Carlsson 1979; Scallan and Grignon 1979). Torgnysdotter and Wågberg (2003) showed that ionised groups, located in the most external part of the fibre surface, will lead to a higher joint strength between the fibres probably due to a swollen surface layer of the fibres. Furthermore, increasing the charge of the fibres leads to a softening (Hammar, et al. 1996) of the fibre wall and hence to an increased flexibility of the fibres (Broderick et al. 1996; Emerton 1951; Laine and Stenius 1997). The charges of the fibres will also cause an electrostatic repulsion between the fibres as long as water is present in the system (Van Oss 1994; Wågberg and Annergren 1997). This means that the effect of the charge is two-fold and that the molecular contact area, so crucial for paper strength, will be deter- 
mined by the softness of the fibre surface, the normal forces between the fibres in the contact zone, the capillary forces, the electrostatic repulsion between the fibres and the van der Waals attraction between the fibres (Wågberg, Annergren 1997). It should be noted though that the van der Waals interaction between highly swollen gels, i.e. fibres in the present case, will be very small. The effective Hamaker constant for the cellulose water system will be less than $10 \%$ of the value between dry cellulose surfaces in vacuum assuming that the cellulose concentration in the outer layers of the fibre wall is $30 \%$ by weight. It is likely that the cellulose concentration is even lower in the outermost layers of swollen fibres. Furthermore, it has been shown that the interaction between macroscopic gels of similar charge in water is totally dominated by electrostatic interactions and the hydration these charges induce in combination with adsorption/desorption phenomena on the gel surfaces (Gong and Osada 1998; Gong et al. 1999).

The swelling of the fibre wall and the fibre surface is determined both by the chemical composition of the fibre wall and the processing of the fibres. Different pulping techniques lead to differences in the charge concentration of the fibre wall. This has been shown to significantly affect the swelling of the fibre wall (Engstrand et al.1991; Gellerstedt and Lindfors 1991; Laine 1996). The internal network strength of the fibre wall will also affect the swelling of the fibres (see for example Wågberg and Annergren 1997). It has been previously shown (Nazhad and Paszner 1994; Scallan and Tigerström 1992; Toven 2003) that recycling of the fibres dramatically increases the inherent network strength of the fibre wall and that this will lead to a lower swelling of the fibres. Different pulping techniques and different fibre treatments will also result in a different water wetting ability of the fibres. During the consolidation between the fibres there is a balance between attractive capillary forces and electrostatic repulsion between the fibres. If the electrostatic repulsion between the fibres is decreased, the fibres will be able to come into closer contact at a certain capillary pressure leading to a more efficient joint formation between the fibres in the fibre/fibre contact (Wågberg and Annergren 1997). Since the fibres are brought together by capillary forces, the contact angle of the water on the fibres will hence significantly contribute to the fibre/fibre consolidation during pressing and drying (Wågberg and Annergren 1997).

The aim of the present work was to determine the relative importance of the electrostatic charge on the forming of joints in paper, therefore joints and sheets were prepared at different ionic strengths and $\mathrm{pH}$ levels. The joint strength between individual fibres was determined and compared with the physical properties of the paper, measured as tensile strength and density. The fibres investigated were regenerated cellulose fibres with their charge varied by carboxymethylation (anionic fibres) and by treatment with glycidyltrimethylamoniumchloride (GTAC) (cationic fibres). The fibre charge together with fibre flexibility and swelling ability were evaluated for the differently treated fibres.

\section{Methods and Materials}

\section{Materials}

The fibres used in these experiments were regenerated cellulosic fibres, Rayon ${ }^{\circledR}$ and Lyocell $^{\circledR}$. Fibres from Svenska Rayon, i.e. Rayon ${ }^{\circledR}$ fibres, were carboxymethylated and have been thoroughly investigated in previous studies where the fibre dimension, cellulose crystallinity, total charge, charge distribution and fibre swelling were determined (Torgnysdotter and Wågberg 2003). The Lyocell fibres used in these experiments were surface and bulk carboxymethylated by the same method as previously outlined (Torgnysdotter and Wågberg, 2003). Some of the Lyocell fibres were also cationised according to the European patent EP 0582624 B1 using glycidyltrimethylamoniumchloride (GTAC). It was only possible to perform the cationisation as bulk charging and therefore only results for bulk charged GTAC fibres will be presented. The Lyocell ${ }^{\circledR}$ fibres were kindly supplied by Lenzing AG, Austria, and the fibres were prepared without spin additives. The fibre tow was then cut to different lengths by Bernhard Steffert AB, Sweden.

\section{Methods Fibre characterisation}

The total charge of the carboxymethylated fibres was analysed using conductometric titration (Katz et. al. 1984) while the total charge of GTAC treated fibres was investigated by using nitrogen analysis at Mikro kemi $\mathrm{AB}$, Sweden.

The contact angle of the fibres was determined in deionised water and $0.1 \mathrm{M} \mathrm{NaCl}$ using the Wilhelmy plate method (Miller et al., 1983, Miller 1985). The equipment was a DCA-322 from Cahn Instruments and the contact angle was determined according to Gellerstedt (1999).

The water retention capacity (Scallan and Carles 1972) and the wet fibre flexibility were assessed in order to investigate the effect of the introduced charges on the single fibres.

The wet fibre flexibility was investigated using the Fibremaster Analysis equipment where the form factor of the fibres was measured at two different flow rates (Fransson et al. 1992).

\section{Paper properties and joint strength measurement}

Handsheets were prepared in the Rapid-Köthen Blattbildner (ISO 5269-2) at different salt concentrations. Furthermore, some sheets were made in a special sheet former (Rundlöf et al. 2000). These sheets were dried according to Rapid-Köthen drying procedure at $100 \mathrm{kPa}$ and $94{ }^{\circ} \mathrm{C}$. Different salt concentrations and $\mathrm{pH}$ intervals $(10 \mathrm{mM} \mathrm{NaCl})$ were used during consolidation. Sheets were also prepared with different amounts of cationic and anionic fibres. One set of Rapid-Köthen hand sheets was sprayed with water and salt water before drying in order to investigate the influence of electrostatic repulsion. The thickness of the sheets was measured according to standard SS 843009. Force-displacement curves were measured according to ISO 52:70. 
The fibre crosses were prepared according to the method initially described by Stratton and Colson (1990) except that the fibres were not dyed (Torgnysdotter and Wågberg 2003). After preparation, the fibre crosses were stored at $50 \% \mathrm{RH}$ and $23{ }^{\circ} \mathrm{C}$ until testing. A tensile testing stage was designed at MidSweden University for fibre strength and fibre cross testing. One of the stage jaws was held stationary while the other was displaced at $2 \mu \mathrm{m} / \mathrm{s}$ during testing. A load cell from Sensotec $^{\circledR}$ with a working range of 0-150 grams was used. The sample was glued to the table of the load bench with Loctite $401{ }^{\circledR}$ glue. For each measuring point 20-30 fibre crosses were tested.

\section{Results}

\section{Joint and paper properties}

In order to clarify the importance of the electrostatic interactions during sheet forming, a number of model experiments were conducted. In these experiments, both surface and bulk-charged fibres were investigated, as well as the sign of the charges. The ionic strength and $\mathrm{pH}$ of the solution was also altered since these parameters are known to have a major influence on electrostatic interactions. Since one of the major aims of the present work was to create a link between joint strength and paper strength, both joints and sheets were prepared under the same conditions. Fig 1 shows how fibre joint strength and paper tensile strength were dependent on the ionic strength for surface- and bulk-charged Rayon fibres. The results show that the different types of fibres behaved differently as salt was present during sheet forming. As salt was added, the use of surface-charged fibres resulted in weaker joints and weaker paper. The bulk-charged fibres, however, showed increased paper strength upon salt addition despite a decreased joint strength. Fig 2 shows the influence of $\mathrm{pH}$ on the strength of fibre/fibre joints and papers made from the differently treated fibres. The joint strength of surface- and bulk-charged fibres as well as paper tensile index of surface-charged fibres had

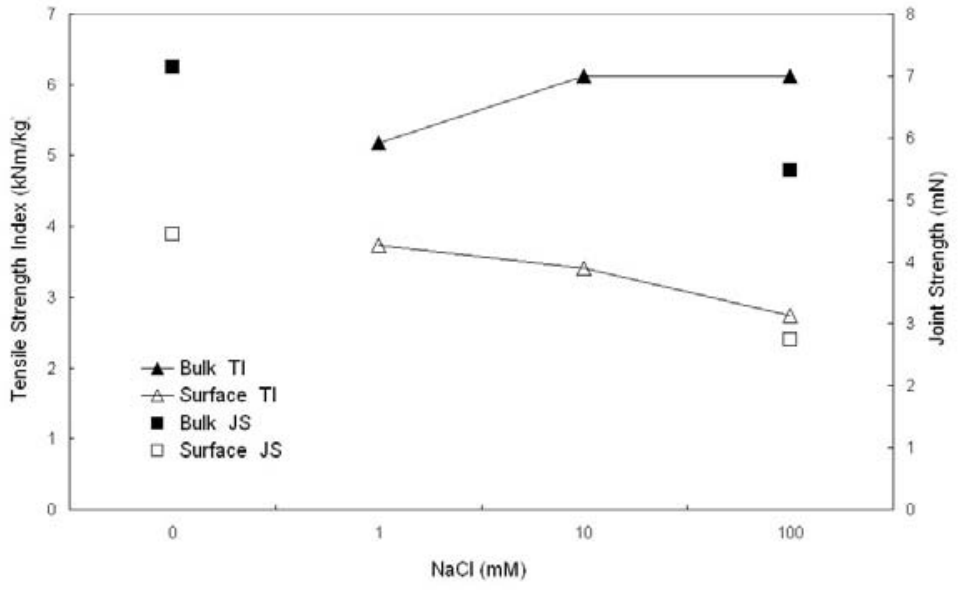

Fig 1. Tensile strength index (TI) and joint strength (JS) of surface- and bulk-charged Rayon fibres at different ionic strength and $\mathrm{pH}$ 7. The variation coefficient of the jointstrenght varies from $20-43 \%$ while it varies from $5-10 \%$ for tensile strength index of the paper; the sheets were made in the Rapid Köthen.
Table 1. Densities of sheets prepared from Rayon fibres at different ionic strengths and $\mathrm{pH}(\mathrm{NaCl}$ concentration of $10 \mathrm{mM})$. The variation coefficient of the density was not higher than $3 \%$ for any of the sheets except for surface-charged rayon fibres at the ionic strength $0.1 \mathrm{M} \mathrm{NaCl}$ where the variation coefficient was $8 \%$.

\begin{tabular}{rll|lll}
\hline \multicolumn{5}{c}{ Sheet Density $\left(\mathrm{kg} / \mathrm{m}^{3}\right)$} \\
\hline $\mathrm{pH}$ & $\begin{array}{l}\text { Surface } \\
\text { Charged } \\
\text { Fibres }\end{array}$ & $\begin{array}{l}\text { Bulk } \\
\text { Charged } \\
\text { Fibres }\end{array}$ & $\begin{array}{l}\mathrm{NaCl} \\
(\mathrm{mM})\end{array}$ & $\begin{array}{l}\text { Surface } \\
\text { Charged } \\
\text { Fibres }\end{array}$ & $\begin{array}{l}\text { Bulk } \\
\text { Charged } \\
\text { Fibres }\end{array}$ \\
\hline 3.4 & 393 & 412 & 0,8 & 310 & 420 \\
6.7 & 384 & 409 & 10 & 314 & 417 \\
10.3 & 397 & 450 & 100 & 333 & 445 \\
\hline
\end{tabular}

a maximum at about $\mathrm{pH} 7$ whereas the tensile index of the paper from the bulk-charged fibres had a minimum at about $\mathrm{pH}$ 7. Table 1 shows the influence of the ionic strength and $\mathrm{pH}$ on sheet density for sheets made from the Rayon fibres. The density of the surface-charged and bulk-charged fibres was unaffected by the salt concentration up to $10 \mathrm{mM} \mathrm{NaCl}$ while the density is increased with a $0.1 \mathrm{M} \mathrm{NaCl}$ addition. It can also be seen in the table that the density is considerably higher for bulkcharged fibres compared to surface-charged fibres. The density of sheets from the bulk-charged fibres exhibits a shallow minimum at a $\mathrm{pH}$ of about 7 while the density for the surface-charged fibres was basically unaffected by the $\mathrm{pH}$.

For a deeper knowledge of the importance of electrostatic interactions during paper forming, a mixture of cationic and anionic Lyocell fibres was used to form sheets at different ionic strengths. Type of charges (i.e. cationic or anionic fibres), charge distribution of the anionic fibres i.e. bulkcharged or surface-charged (cationic fibres with bulk charge only) and the salt concentration were varied in these experiments. Fig 3 shows how the joint strength and tensile strength varied with the amount of cationic fibres in the sheets, which also leads to different amount of charges in the sheet. For the joints, $0 \%$ cationic fibres was equivalent to two anionic fibres in the fibre cross, $50 \%$ was one 


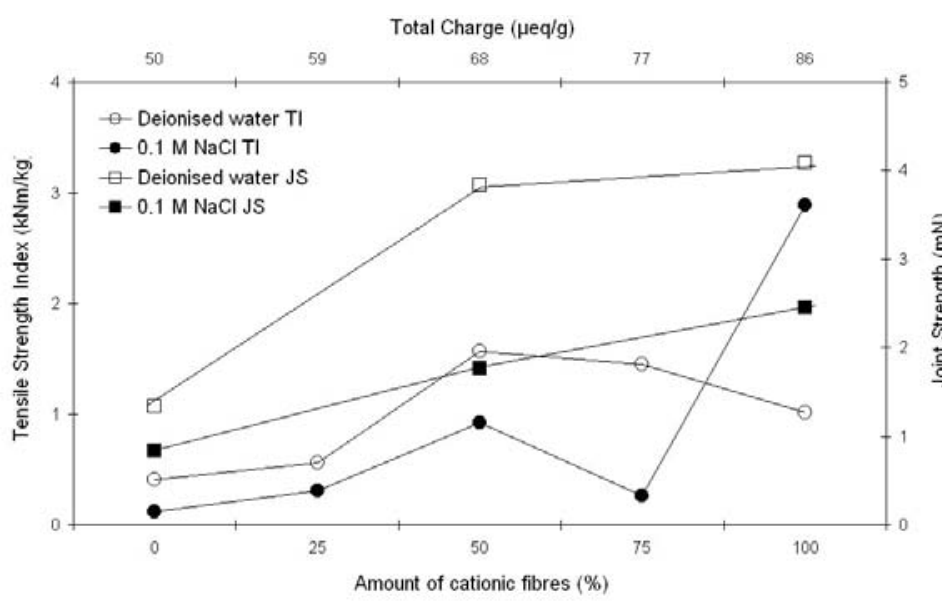

Fig 3. Tensile strength index (TI) and joint strength (JS) for different combinations of anionic and cationic fibres (Lyocell fibres). The sheets and joints were made in deionised water and $0.1 \mathrm{M} \mathrm{NaCl}$ at $\mathrm{pH} 7$. The sheets were formed in the device described by Rundlöf et al. (2000). The variation coefficient of the jointstrengh was around $40 \%$ and $15 \%$ for the sheetstrenght.

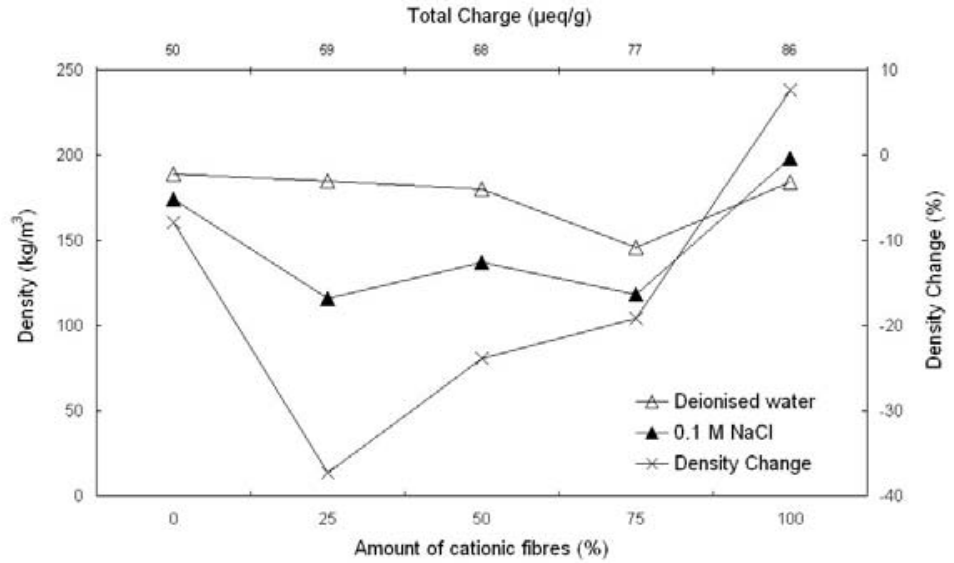

Fig 4. Sheet density for the Lyocell sheets in fig. 3 prepared in deionised water and $0.1 \mathrm{M} \mathrm{NaCl}$ at $\mathrm{pH}$ 7, the change in sheet density is also shown. The sheets and joints were made in deionised water and $0.1 \mathrm{M} \mathrm{NaCl}$. The variation coefficient of the density was around $10 \%$.

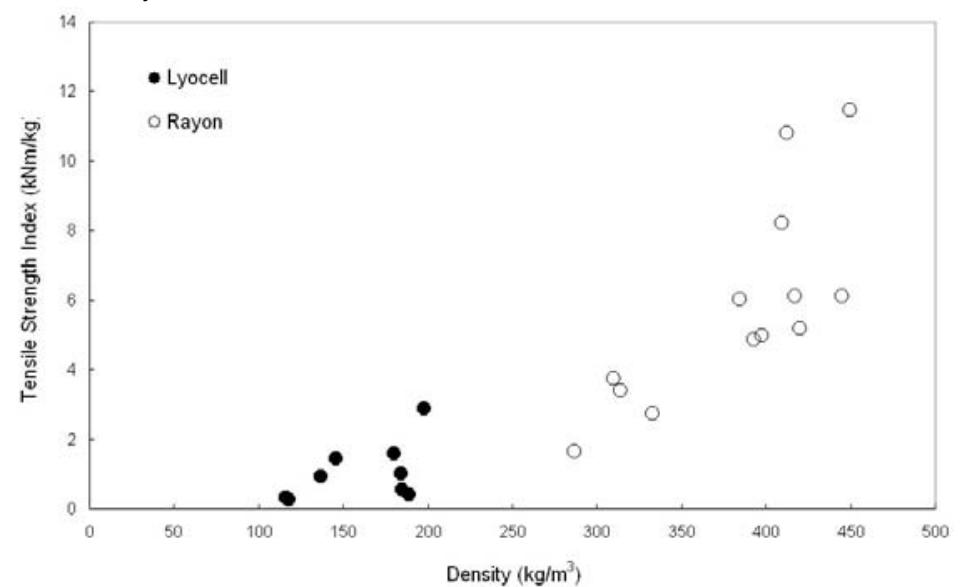

Fig 5. Tensile strength index versus density for a summary of all the investigated sheets of Rayon and Lyocell fibres.

anionic and one cationic fibre and $100 \%$ was two cationic fibres. As can be seen in Fig 3 the strengths of joints and strength of papers from fibres with equal charge showed the same behaviour as in Fig 1, i.e. increasing salt concentration reduced the joint strength but increased the paper strength for bulk-charged fibres $(100 \%$ cationic fibres). The mixtures containing $50 \%$ and $75 \%$ cationic fibres showed the largest decrease in tensile strength index when changing from deionised water to $0.1 \mathrm{M} \mathrm{NaCl}$. Fig 4 shows the density and the change in density for the sheets corresponding to the results shown in Fig 3. It can be seen that the density decreased for mixtures of cationic and anionic fibres when the ionic strength was increased. For the sheets containing $100 \%$ cationic fibres the density was slightly increased when salt was added during sheet forming.

A summary of the relationship between tensile strength and density of the papers prepared from all of the fibres discussed so far is shown in Fig 5, which shows that there is a correlation between sheet strength and density in this density interval. The detected differences in tensile strength for sheets prepared with Lyocell sheets and Rayon were hence probably due to the difference in sheet density. It must be stated that the strengths of the papers were very low compared to papers made of natural fibres but it should also be stressed that the detected absolute changes are significant, repeatable and reproducible.

\section{Fibre properties}

The fibres were also characterised with respect to total charge, water retention value (WRV), fibre geometry, wet fibre flexibility and contact angle of the fibres with deionised water and $0.1 \mathrm{M} \mathrm{NaCl}$. In Table 2 these properties are shown for different salt contents. The wet fibre flexibility and WRV of the fibres increased drastically for the bulk-charged fibres, due to increased total charge of the fibres whereas there was only a minor change detected for the surface charged fibres. Addition of salt had no affect on the flexibility neither for the bulk-charged fibres nor for the surface-charged fibres but the salt addition decreased the swelling measured as WRV from $1.4 \mathrm{~g} / \mathrm{g}$ to $1.2 \mathrm{~g} / \mathrm{g}$ for the bulk charged fibres. Table 2 also shows that the Rayon fibres exhibited a much higher flexibility than Lyocell fibres despite the lower slenderness. It was also determined that the contact angle of the Lyocell fibres decreased with carboxymethylation and cationisation. Furthermore, the contact angle of the fibres was higher in salt water compared to deionised water.

\section{Discussion}

As was shown earlier in the results section, the change in properties of the paper from bulk-charged fibres and surface-charged fibres was different when the salt concentration during sheet preparation was increased or when the $\mathrm{pH}$ was decreased. Generally the strength of sheets from surface-charged fibres decreased whereas the sheets from bulk-charged fibres showed an increase in strength as the salt concentration was increased or the $\mathrm{pH}$ was decreased. There might naturally be several reasons to these changes and in the following dis- 
Table 2. Fibre charge, wet fibre flexibility, fibre dimensions, water retention value of surface and bulk charged fibres at different salt concentrations. The contact angles were analysed for the Lyocell fibres in water and $0.1 \mathrm{M} \mathrm{NaCl}$. The sign + stands for cationic charge and - for anionic charge. The measurements were made at $\mathrm{pH} 7$.

\begin{tabular}{llllllllll}
\hline $\begin{array}{l}\text { Fibre } \\
\text { type }\end{array}$ & $\begin{array}{l}\text { Charge } \\
\text { character }\end{array}$ & $\begin{array}{l}\mathrm{NaCl} \\
(\mathrm{mM})\end{array}$ & $\begin{array}{l}\text { Total } \\
\text { charge } \\
(\mu \mathrm{eq} / \mathrm{g})\end{array}$ & $\begin{array}{l}\text { Wet } \\
\text { fibre } \\
\text { flexibilty }\end{array}$ & $\begin{array}{l}\text { Fibre } \\
\text { width } \\
(\mu \mathrm{m})\end{array}$ & $\begin{array}{l}\text { Fibre } \\
\text { length } \\
(\mathbf{m m})\end{array}$ & $\begin{array}{l}\text { Form } \\
\text { factor }\end{array}$ & $\begin{array}{l}\text { WRV } \\
\mathrm{g} / \mathrm{g}\end{array}$ & $\begin{array}{l}\theta\left({ }^{\circ}\right) \\
\text { Deionised } \\
\text { water } / \mathbf{0 . 1} \mathbf{M} \\
\mathrm{NaCl}\end{array}$ \\
\hline Rayon & Surface - & 0.8 & 76 & 2.0 & 37.6 & 4.1 & 95.1 & 0,8 & \\
Rayon & Surface - & 0.8 & 100 & 2.4 & 38.2 & 3.8 & 96.6 & 0,8 & \\
Rayon & Surface - & 50 & 100 & 2.2 & 39.0 & 4,0 & 96.1 & - & \\
Rayon & Surface - & 140 & 100 & 2.5 & 37.3 & 3,9 & 95.0 & 0,8 & \\
Rayon & Bulk - & 0.8 & 550 & 5.3 & 41.0 & 4,0 & 96.4 & 1,4 & \\
Rayon & Bulk - & 50 & 550 & 5.1 & 42.2 & 4,0 & 94.1 & - & \\
Rayon & Bulk - & 140 & 550 & 5.4 & 42.0 & 3,9 & 95.0 & 1,2 & \\
Lyocell & Surface - & 0.8 & 3,5 & 1,1 & 28.5 & 4.0 & 96.2 & - & $54 /$ \\
Lyocell & Surface - & 0.8 & 50 & 0,8 & 26.3 & 4.1 & 96.5 & - & $24.5 / 28.8$ \\
Lyocell & Bulk + & 0.8 & 86 & 1,9 & 28.6 & 4.0 & 88.5 & 0,6 & $34.8 / 44.9$ \\
\hline
\end{tabular}

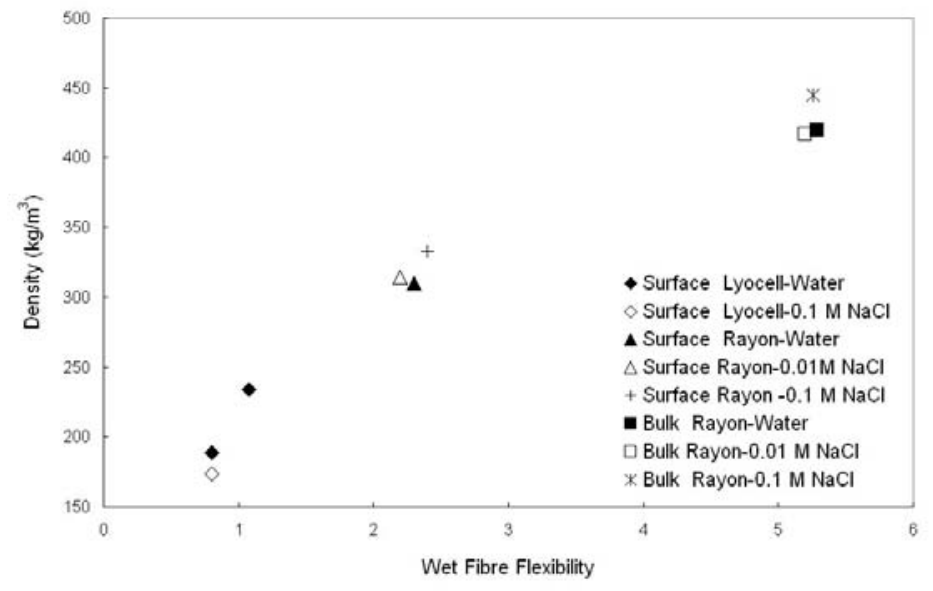

Fig 6. Sheet density versus wet fibre flexibility for a summary of Lyocell and Rayon fibres. The measurements were made at different salt contents at $\mathrm{pH} 7$.

cussion the influence of fibre swelling and its influence on wet fibre flexibility and the influence of electrostatic interactions during joint and sheet forming will be treated separately.

\section{Wet fibre flexibility}

When the charge of the bulk of the fibre is increased there is a significant increase in the swelling of the fibres as shown in Table 2 whereas the surface-charge has no influence on the swelling of the fibres at all. Due to the imbibition of water into the fibres, the flexibility of the fibres is increased and this will in turn lead to a higher density of the formed sheets as shown in Fig 6. A larger flexibility of the fibres means that the fibres can pack
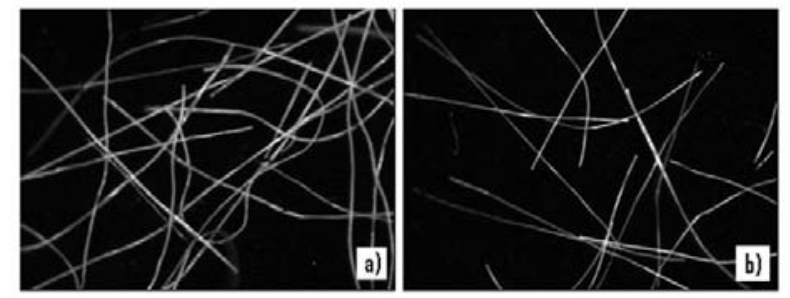

Fig. 7 a and b. Microscope pictures of (a) bulk-charged Rayon fibres and (b) surface-charged Rayon fibres in a dry sheet. more efficiently during sheet preparation and this also leads to a larger number of contacts between the fibres in the dry sheet. In turn this means that in addition to the increased joint strength, due to the increased charge density, there will also be an increase in the number of possible contacts between the fibres when the bulk-charge of the fibres is increased.

In Fig 6 it can also be seen that there was no change in fibre flexibility when the ionic strength of the water phase was changed. This indicates that once the fibres have been expanded due to the increased charge and hence gain in flexibility, they will not lose flexibility even though there is a deswelling due to the increased salt concentration.

In order to get a more direct presentation of the change in fibre flexibility with the change in charge, microscopy images of the fibres were collected. These images are shown in Fig 7 a and Fig $7 b$ and as can be seen the bulk-charged fibres (7a) are more curled, i.e. more flexible, than the surfacecharged fibres (7b).

\section{Effect of ionic environment and charge interac- tions during joint and paper forming}

The joint strength and tensile strength index for surface- and bulk-charged Rayon fibres is shown in Fig 8. The joint strength increased with the surface charge of the fibres as did the tensile strength index. For the bulk charged fibres there was also an increase in joint strength and tensile strength. By adding salt to the fibre dispersion or adjusting the $\mathrm{pH}$ to lower values less advantageous for fibre swelling, joint strength of both surface-charged and bulk-charged fibres decreased. The paper strength, however, decreased for the surface-charged fibres but increased for the bulk-charged fibres. Considering the above results, there seems to be a fundamental difference for the influence of ionic strength on joint strength and sheet strength for the differently charged fibres. In order to sort out this difference between the two types of fibres it is necessary to return to what con-

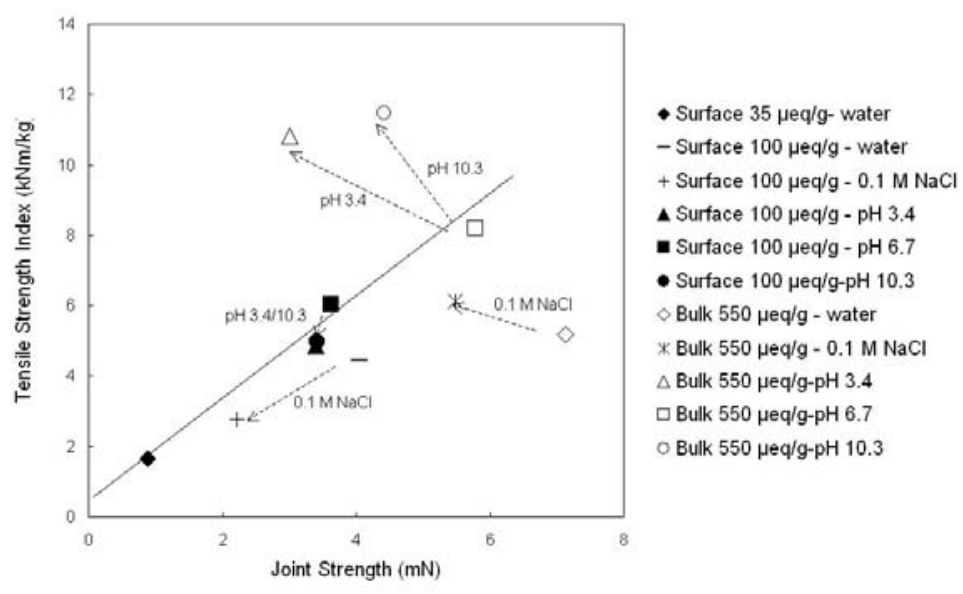

Fig 8. Tensile strength index versus joint strength of surface and bulk charged Rayon fibres at different ionic strength and $\mathrm{pH}$, redrawn from Fig 1 and Fig 2. The charge and charge distribution of the fibres is shown in the legend of the figure. The arrows indicate the change in conditions during forming of the joints and papers. 
stitutes the strength of the sheets made from these fibres. First of all, the total strength in the sheet will be determined by the total number of efficient contacts per fibre, which is here referred to as joints, the molecular contact area in the contact zone and the work of adhesion in the area of molecular contact. This means that the primary reason for the joint and sheet strength increase, for the surface-charged fibres, is a more favourable interaction in the fibre/fibre joints. There was no increase in fibre flexibility which means that there was no change in the number of efficient contact points per fibre, with an increasing surface charge. Therefore it may be safely suggested that the increase in the joint strength increased the paper strength, for these fibres.

For the bulk charged fibres there was an increase in fibre flexibility leading to a higher probability to form contacts / fibre. But, the probability of the formation of an efficient joint in every possible contact point will decrease due to the rather large electrostatic repulsion for these types of swollen gels (Wågberg and Annergren 1997; Gong and Osada 1998; Gong et al. 1999). As the ionic strength increased or the $\mathrm{pH}$ was adjusted to levels below the average $\mathrm{pK}$ value of the charged groups, the electrostatic repulsion between the fibres decreased and the probability of the creation of a joint in every possible contact point increased since the flexibility was unaffected by the decreased electrostatic interactions. Therefore, the efficient number of contact points/fibre increased and this is most probably why sheet density and tensile strength index were increased with an increase in salt concentration.

Surface de-swelling occurred for the bulk-charged fibres as well, but as the sheet strength increased with ionic strength and $\mathrm{pH}$ adjustment, the forming of efficient joints between the fibres dominated over the decrease in joint strength for these fibres.

To test the hypothesis of fibre flexibility and probability of joint formation, sheets were sprayed with water and salt water after forming of the wet contact points in the sheet but prior to drying. The results in Table 3 show that the density and number of contact points/fibre were unaffected for the different fibre types, while the tensile index decreased slightly with salt addition for both

Table 3. Sheet density, number of contact points and tensile strength index of sheets sprayed with water and salt water after sheet forming, the results are presented with 95\% confidence limits. The number of contact points/fibre was calculated according to Rigdahl and Hollmark (1986).

\begin{tabular}{lcccc}
\hline & $\begin{array}{c}\text { Surface charged } \\
\text { fibres }\end{array}$ & $\begin{array}{c}\text { Surface charged } \\
\text { fibres }\end{array}$ & $\begin{array}{c}\text { Bulk charged } \\
\text { fibres }\end{array}$ & $\begin{array}{c}\text { Bulk charged } \\
\text { fibres }\end{array}$ \\
\hline $\begin{array}{l}\text { Solvent } \\
\text { Density } \\
\left(\mathrm{kg} / \mathrm{m}^{3}\right)\end{array}$ & $\begin{array}{c}\text { Deionized water } \\
\text { Contact }\end{array}$ & $0,1 \mathrm{M} \mathrm{NaCl}$ & Deionized water & $0,1 \mathrm{M} \mathrm{NaCl}$ \\
$\begin{array}{l}\text { points/fibre } \\
\begin{array}{l}\text { Tensile Index } \\
(\mathrm{kNm} / \mathrm{kg})\end{array}\end{array}$ & $2,6 \pm 0,19$ & $348 \pm 6$ & $367 \pm 5$ & $369 \pm 7$ \\
\hline
\end{tabular}

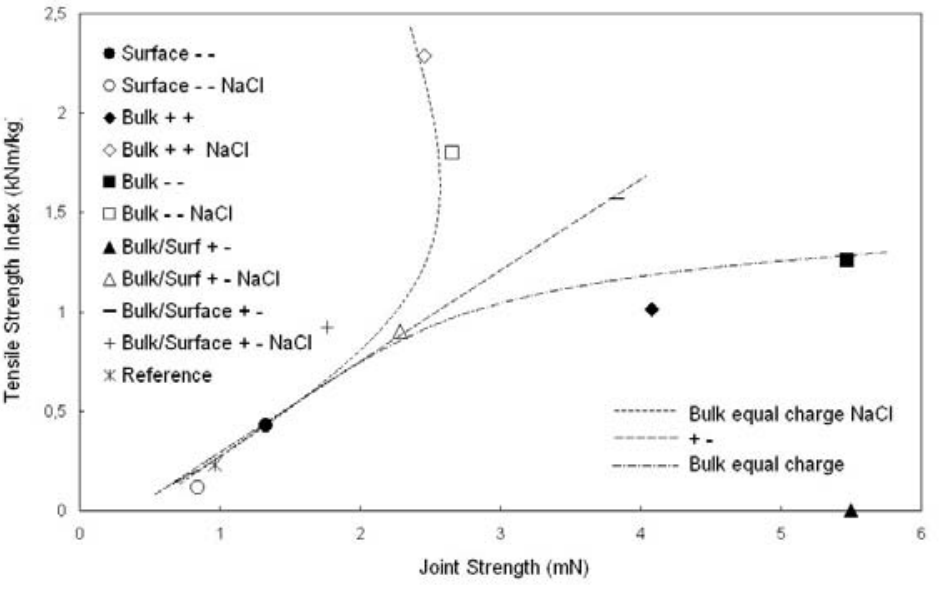

Fig 9. Tensile strength index versus joint strength for different combinations of anionic and cationic Lyocell fibres. The sheets and joints were made in deionised water and $0.1 \mathrm{M} \mathrm{NaCl}$ at $\mathrm{pH} 7$. The sheets were formed in the device described y Rundlöf et al. (2000). The variation coefficient of the jointstrenght was around $40 \%$ and $15 \%$ for the sheetstrenght. It was not possible to prepare sheets of $5 \%$ bulk charged anionic/ cationic fibres (bulk +- ) due to the high degree of occulation. By adding salt the attraction between the fibres during sheet forming ccreased and hence it was possible to form a paper without large fibre flocks. e reference in the diagram is untreated Lyocell fibres.

surface and bulk charged fibres. The decreased tensile strength index was most probably due to decreased joint strength.

It must be stressed that the effect of salt addition on sheet strength for sheets from bulk carboxymethylated fibres has been found in several experimental series and the effect is very similar to the effect on friction coefficients between macroscopic gels (Gong and Osada 1998; Gong et al. 1999). However it is not clear if the effect for the fibres is a) a decreased electrostatic repulsion that allows the fibres to get into intimate contact earlier during the consolidation and drying or $b$ ) a higher friction coefficient between the fibres that prevents the fibres from sliding against each other during sheet forming. A more efficient interlocking between the fibres would utilise the normal forces between the fibres better and this in turn would lead to a more efficient joint formation in the fibre/fibre contacts. It is suggested that these two effects are studied even more in detail in future investigations.

\section{Influence of electrostatic interactions between dissimi- larly charged fibres during joint and paper forming}

By mixing different ratios of cationic and anionic fibres in sheets at different salt concentration, the influence of electrostatic attraction between the fibres could be evaluated for both joint and paper strength. Fig 9 shows how tensile strength versus joint strength changed with the sign of the charge of the fibres and salt concentration. An increased ionic strength had a larger negative effect on the joint strength for a joint of one cationic and one anionic fibre compared to equally charged fibres. The same was true concerning paper strength, i.e. increasing the ionic strength in solutions during preparation of sheets of equal bulkcharge increased the paper strength while the strength decreased for sheets composed of a mixture of fibres with dissimilar charge or for equally surface charged fibres. 


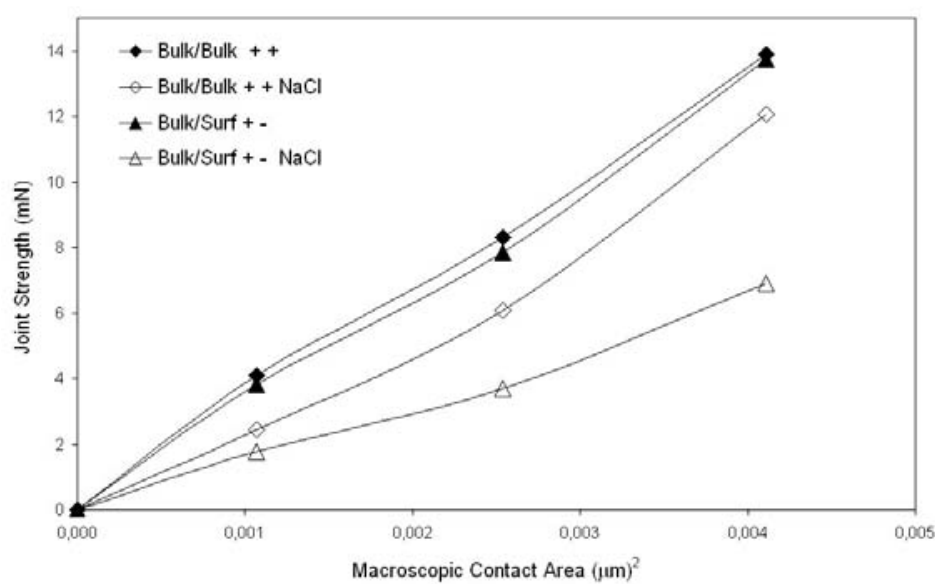

Fig 10. Joint strength versus macroscopic contact area of the joint, the slope of the curve is hence the specific joint strength of the fibre/fibre joint. The different contact areas were achieved using different dimensions of the Lyocell fibres. The joint strength has been determined for different combinations of anionic (surface-charged fibers) and cationic fibres (bulk-charged fibers), the joints were formed in deionized water and $0.1 \mathrm{M} \mathrm{NaCl}$ at $\mathrm{pH} 7$. The variation coefficient of the jointstrenght was around $40 \%$.

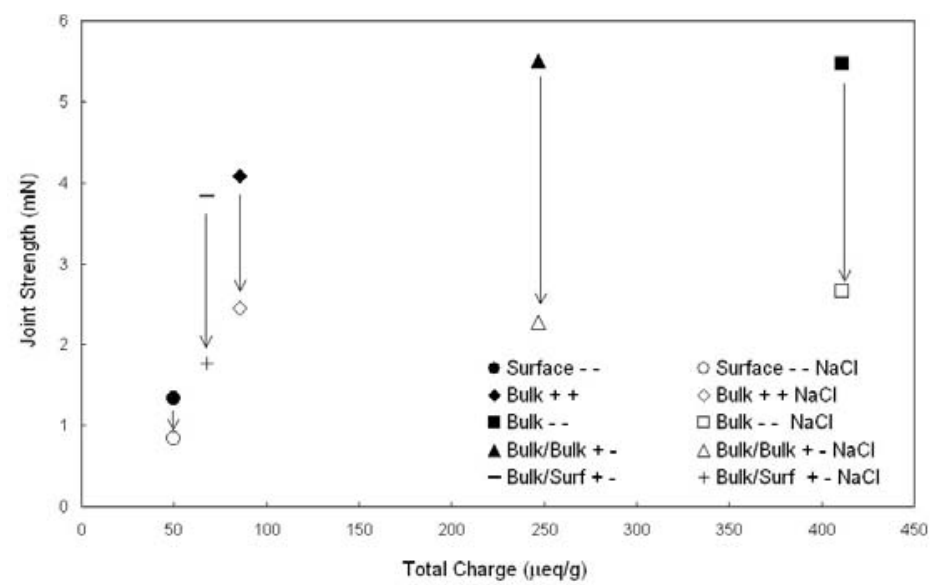

Fig 11. Joint strength versus charge of the Lyocell fibres. The joint strength has been determined for different combinations of anionic and cationic fibres in deionized water and $0.1 \mathrm{M} \mathrm{NaCl}$ at $\mathrm{pH}$ 7. The arrows indicate the change in condition during forming of the joints. The variation coefficient of the jointstrenght was around $40 \%$.

Again it is suggested that a combination of changes in joint strength and formation of efficient joints in the fibre/fibre contacts can be used to explain the detected effects of the salt addition. For the bulk-charged fibres of similar charge there is again a decrease in joint strength with salt addition but due to decreased electrostatic interaction there is a higher probability that efficient joints are formed in the contact points.

For fibres of dissimilar charge an interesting effect can be observed. As shown in Fig 9 the sheet strength of bulk/surface + - fibres is relatively high at a certain joint strength. This again shows the importance of the charge interactions during sheet consolidation and drying, i.e. a strong electrostatic attraction between the fibres forms more easily efficient joints in the fibre/fibre contacts. This is further supported by a large decrease in both joint and sheet strength for this fibre consolidation with increasing salt concentration.

Additional experiments were conducted using fibres with different fibre-diameter and varying charge density and sign of the charges in order to further estimate the relative importance of electrostatic repulsion / attraction and surface swelling/de-swelling on the strength of the formed joint. From the slope of the curves in Fig 10, it can be estimated how the specific joint strength was affected as salt was added, while Fig 11 shows the influence of total charge on joint strength. The graphs in both Fig 10 and Fig 11 indicate that the specific strength of joints with one negatively and one positively charged fibre were further reduced as salt was added compared to the joints with two equally charged fibres. In Fig 11 it is also shown that a combination of a surface charge and a positive interaction between anionic and cationic charged fibres (Bulk/Bulk +-) results in a high joint strength despite a relatively low total charge compared to bulk charged fibres of equal charge (Bulk--). This shows that surface swelling and electrostatic attraction can give stronger joints. However, as the ionic strength was increased both these effects were almost eliminated resulting in a larger decrease in strength for this combination of the charges. This is also supported by the results in Fig 8, where the addition of salt decreases the joint strength to a larger extent for surface-charged fibres than for bulk-charged fibres. This may be due to decreased electrostatic interactions between the fibres giving a smaller decrease in the joint strength for bulk charged fibres of similar charge, compared to surface charged fibres, as the ionic strength increases.

\section{Conclusions}

The influence of the electrostatic interactions during paper formation was investigated in this work. Fibre-fibre crosses and sheets were prepared from regenerated cellulose fibres of different charge distribution (i.e. surface-charge and bulk-charge) and differently charged character $(+/-)$ at different electrolytic environment i.e. salt concentration and $\mathrm{pH}$ during sheet forming. In order to clarify the observed joint and sheet properties, the chemical and mechanical pulp properties e.g. charge and wet fibre flexibility were characterised.

The investigations showed that the joint strength was dependent on the fibre surface softness which followed the accepted theories of swelling and electrostatic interaction. The bulk-charges of the fibres were shown to have a more complex role during joint and sheet formation by affecting the wet fibre flexibility. The charges located inside the fibre also greatly influenced the electrostatic interactions between the fibres. These factors showed a high importance for the paper properties by affecting the number of contact points in the sheet and hence the sheet density. The softness of the surface will hence have a high importance for the properties of the single joint in the paper while the bulk properties will 
affect the possibility of the fibres to form contact points in the sheet, together theses factors will influence the paper properties concerning both tensile strength and sheet density.

\section{Acknowledgement}

Thanks are extended to Staffan Nyström, Mid-Sweden University, Sundsvall for designing the joint measurement equipment. Anna Bagger-Sjöbäck and Lars Nilsson, SCA for contact angle measurements of fibres. The authors acknowledge Dr. Shannon Notley for linguistic revision. Co-workers at FSCN and KTH and Kent Malmgren, SCA Research, are appreciated for fruitful discussions. Professor Myat Htun is acknowledged for comments and ideas during the work. FSCN (Fibre Science Communication Network) is last but not least thanked for financial support.

\section{Literature}

Broderick, G., Paris, J., Valade, J. and Wood, J. (1996): Tappi J., 79(1), 161-169. Emerton, H.W. (1957): Fundamentals of the beating process, British Paper and Board Ind. Res. Ass.

Engstrand, P., Sjögren, B., Ölander, K., Htun, M. (1991): Significance of carboxylic groups for the physical properties of mechanical pulp fibres, 6th International Symposium on Wood and Pulping Chemistry Proceedings, Appita, Parkville, Victoria, Austrailia, , vol.1, p.75.

Fransson, P-I, Karlsson, H,and Kastre, L. (1992): Patent, US 5331405.

Gellerstedt, F. (1999); Licentiate thesis, Chalmers University of Technology, Göteborg.

Gellerstedt, G. and Lindfors, E-L. (1991): "On the Structure and reactivity of residual lignin in kraft pulp fibres", International Pulp Bleaching Conference, Stockholm, Sweden. June 11-14, 1991, Proceedings, vol1, p.73.

Grignon, J. and Scallan, A.M. (1980): J. Appl. Polymer Sci. 25:829.

Gong, J. and Osada, Y., J. (1998): Chem. Phys. 109(18), 8062-8068.

Gong, J., Kagata, G. And Osada, Y. (1999): J. Phys. Chem. B. 103(9), 6007-6014. Hammar, L.Å., Htun, M., Ottestam, L., Salmén, L. And Sjögren, B. (1996): J.Pulp and Paper Sci., 22(6), J219-223.

Katz, S., Beatson, R. P., and Scallan, A. M. (1984): Sven. Papperstidn. 87, R48. Kendall, K., "Molecular adhesion and its application- The sticky universe", Kluwer Academic, ISBN 0-306-46520-5, p. 155'.
Kendall, K., "Molecular adhesion and its application- The sticky universe", Kluwer Academic, ISBN 0-306-46520-5, p. 151².

Laine, J. (1996): "The effect of surface chemical composition and charge on the fibre and paper properties of unbleached and bleached kraft pulps" Doctoral thesis, Helsinki University of Technology

Laine, J and Stenius, P. (1997): Paper and Timber, 79(4), p.257-266,

Lindström, T., Carlsson, G. (1978); "The effect of chemical enviroment on fibre swelling", EUCEPA symposium, Warsawa, p.32.

Lindström, T. (1986): In "Paper- Structure and Performance", A. Bristow and P. Kolseth, Eds., Marcel Dekker, Inc. New York, Basel, p.. 75 and p.99.

Miller, B. (1985): In "Absorbancy" Chatterjee, P.K. Ed., Amsterdam, Elsevier Sci. Pub. 121-147.

Miller, B., Penn, L.S. and Hedvat, S. (1983): Colloids and Surfaces, 6, 49-61,

Nazhad, M. and Paszner, L. (1994); Tappi J. 77(9).

Page, D.H. (1969): Tappi, 52, 674.

Rigdahl, M. and Hollmark, H. (1986): "Network Mechanics", In "Paper, structure and properties", Bristow, J.A. and Kolseth, P. (Ed.), Marcel Dekker, inc., New York, USA, ISBN 0-8247-7560-0, p.246.

Rundlöf, M., Sjölund, A-K., Stöm, H., Åsell, I. And Wågberg, L. (2000): Nordic Pulp Paper Res. J., 15(4).

Scallan, A.M. and Carles, J.E. (1972): J. Sven. Papperstidn. 75, p.699.

Scallan, A.M., and Grignon, (1979): J.:Sven. Papperstidn. 82(3).

Scallan, A.M. and Tigerström, A. (1992): J. Pulp Paper Sci., 18(5), J188.

Stratton, R. A., Colson, N. L. (1990); Mat. Res. Soc. Symp. Proc., 197, p.173-181. Torgnysdotter, A. and Wågberg, L. (2003): Nordic Pulp Paper Res. J.,18(4). Toven, K. (2003): Tappi J., 2(2), p. 3-7.

Wahlström, B. (1989): "An overview of web consolidation", Paper presented at 75th Annual Meeting, Technical Section, held in Montreal, Canada, 31 Jan.-3 Feb. (1989), vol. B, pp B351-379 [Montreal, Canada: Canadian Pulp and Paper Association, vol. B, , 402pp (676(71)) (6667)].

Van 0ss, C.J. (1994): Internal forces in aqueous media, ISBN 0-8247-9168-1. Wågberg, L: and Annergren, G. (1997): "Physico-chemical characterisation of papermaking fibres", In "Fundamentals of Papermaking Materials", C.F. Baker (Ed.), Transactions of the 11th Fundamental Research Symposium held at Cambridge, Pira International. , Leatherhead UK, ISBN 185802209 6, p.1-82.

Manuscript received January 29, 2004 Accepted June, 2004 